\title{
Implementing the Mental Health Act 2001: What should be done? What can be done?
}

\author{
Dr Kathleen Ganter, Dr lan Daly, Dr John Owens
}

Ir J Psych Med 2005; 22(3): 79-82

\section{Introduction}

The Editorial in this month's journal highlights the key issue for psychiatry in Ireland at the present time - the implementation of the 2001 Mental Health Act. Ireland has been operating under antiquated mental health legislation and in contravention of the basic human rights of people with mental illness. The positions and genuine concerns of the representative bodies of pychiatrists in Ireland, the Irish College of Psychiatrists and the Irish Psychiatric Association, together with those of the Mental Health Commission, regarding the implementation of the new legislation were sought and their responses are printed below. There is mostly common ground, the arguments not being about the imperative necessity for the Act's implementation but when and how it must be effected. It is hoped that this editorial will spur further constructive debate about this issue in these pages and hasten the achievement of what is a common goal of all psychiatrists in Ireland - the implementation of modern mental health legislation that protects the human rights of people with mental illness and works for all stake-holders of a 21 st century mental healthcare system.

\section{Prof Brian Lawlor}

Editor-in-Chief

\section{Irish College of Psychiatrists}

The Mental Health Act was passed by both houses of the Oireachtas four years ago, but as yet has not been fully commenced. Ireland has a history of passing mental health legislation and failing to implement it, with Acts on the statute book for 1960 and 1981 . The Irish College in alliance with other mental health advocacy groups such as carers and users groups has been active in calling for improved protection for the rights of the mentally ill.

People with mental disorders are sometimes a danger to themselves or others, or at risk of severe self-neglect unless given psychiatric treatment. Yet because of their illness they may be unwilling or unable to give consent to treatment that is in their best interests. Modern mental health legislation is designed to protect the rights and dignity of such people, and to ensure that they receive the treatment they need. International standards increasingly define as human rights the forms of protection and respect that have always been central to good psychiatric practice. The Irish College of Psychiatrists has been active in pressing for modern legislation over many years and has made submissions to

Dr Kathleen Ganter, Chairman, Irish College of Psychiatrists. Dr Ian Daly, Irish Psychiatric Association. Dr John Owens, Chairman, Mental Health Commission. government concerning ways to make the new legislation more effective in achieving its goals. In a recent judgement, the Supreme Court, noting the very slow progress towards the passage of a modern Mental Health Act, commented that the best is often the enemy of the good, and any new legislation would be better than the moribund and condemned Mental Treatment Act 1945. Psychiatrists have long since come to the same conclusion.

There are therapeutic gains to be made from the implementation of the Mental Health Act 2001 and regardless of these, there are more fundamental obligations to implement the Act because of the need to honour the requirements of the European Convention on Human Rights. Psychiatrists are the experts on how to conduct a proper and ethical professional relationship with mentally disordered patients, particularly concerning the assessment of the capacities, wishes and intentions of the mentally disordered patient. Psychiatrists are trained to listen and respond to patients regarding their treatment needs and choices. Now is the time to translate these long-standing skills and roles into practice within the framework of the Mental Health Act.

There is a substantial task ahead to familiarise ourselves with the language and processes of the new Act. The Irish College of Psychiatrists in association with the Mental Health Commission is developing such a training programme for psychiatrists which should commence in the Autumn. This is likely to be a continuing task since the courts will review and rule on the interpretation of the Act over the coming years, and other legislation is in the offing, including the Criminal Law (Insanity) Bill which has now passed through the Seanad, and recent discussion papers from the Law Reform Commission on the elderly and the mentally disabled who are incapacitated.

For the first-time the Act will apply to children under the age of 16 years. The definition of children has also changed to include those up to the age of 18 years. No guidelines are in place as to how to implement the new Act governing the involuntary detention and treatment of children. It is recognised by all that specifically identified inpatient facilities for children are currently not available and only a very limited number will be available in the foreseeable future.

There are also unresolved issues regarding consent and treatment for people who may have limited or diminished capacity to give consent, the elderly with dementia or the intellectually disabled. Ireland currently has only two approved centres for the inpatient treatment of the intellectually disabled with psychiatric disorders.

The Irish College of Psychiatrists has the utmost concern for the civil and human rights of people who are detained for assessment and treatment, however, this is also balanced by our extreme concern for the right to treatment to restore 
autonomy and dignity. This principle of reciprocity cannot be honoured unless adequate treatment resources are available. The Mental Health Commission received $€ 15$ million to implement the Act, frontline services received nothing.

Other organisations will point out that to implement the act requires administrative resources and medical time. The Irish College of Psychiatrists seeks to ensure through training that the professional skills and responsibilities of the psychiatrist are recognised as the leader in preparing treatment and care plans and in working with the Act, while maintaining a therapeutic relationship with the patient and the patient's family and carers.

\section{Dr Kathleen Ganter}

\section{Chairman}

Irish College of Psychiatrists

\section{Irish Psychiatric Association}

Legislation to replace the outdated 1945 Mental Treatment Act was first drafted in 1981, abandoned, apparently for administrative reasons, and only came into being again two decades later in the new Mental Health Act, 2001.' Psychiatrists have been criticised for delaying its implementation and have been portrayed as a group whose self-interest takes precedence over patients' civil rights. But the issues involved are more complex than that. In his study on American mental health legislation, Paul Applebaum concluded:

"Neither society's interests in providing treatment to mentally ill persons - particularly in the difficult circumstances in which they deny their need for care - nor its interest in protecting their civil rights stands alone. The purpose of mental health law should be to fashion reasonable comprises between these often conflicting desiderata".2

Implementation of such legislation should therefore require input from all parties involved (patients, healthcare professionals, management, etc.) and these parties should be free to voice their concerns. It should be acknowledged openly that, if legislation is to be effective, care and rights cannot stand apart each from the other. Improving rights does not necessarily translate into a high quality environment of care. Eastman and Peay have volunteered the opinion that "...the influence of other disciplines over law is likely to be limited and that, in practice, the law has tended generally to be unresponsive to mental health imperatives". 3

To these considerations can be added other factors of concern to practitioners. We provide care to a group of citizens who continue to remain outside the main thrust of government attention and financial provision. Honouring their civil rights amounts, in practice, to something more difficult than relinquishing traditional medical paternalism. It often translates into a demanding and none-too-clear set of tasks to provide our patients with skills to survive in a community setting and to ensure that their behaviour remains within tolerable (societal) limits. ${ }^{4}$ If members of that small group of detained patients are to be discharged into the community only to have to subject themselves to more subtle forms of compliance and control, it is imperative that this is carried out in conditions that are adequate, respectful and private, as has been proposed in the United Nations (UN) Principles for the Protection of Persons with Mental IIIness. ${ }^{5}$ Overall, then, there is a perception that the legal, civil rights-based narrative of the act is being driven forward with some indifference to clinical imperatives.

The argument will be made that through the setting up the Mental Health Commission (MHC) and widening the scope of the Inspectorate, sufficient provision has been made within the act to deal with these concerns. And the MHC has been vocal in making the case for far-reaching improvement and modernisation of our services. However resource provision is not within the gift of the MHC. Year-on year, the proportion of health funding that is allocated to mental health continues to decline. A recent Irish Psychiatric Association report details long-term inequitable distribution of resources of almost scandalous proportions within our mental health services. ${ }^{6}$ Poor governance of this sort does little to engender trust among healthcare professionals. Likewise, the timing of the new Act coincides almost exactly with the period of greatest upheaval in the structure of health services that this state has seen. Anyone who works within the health service sector will be aware of our current state of almost complete managerial and administrative arrest.

The similarities between the current situation and the circumstances surrounding the introduction of 'Planning for the Future' are instructive. ${ }^{7}$ An imaginative plan, launched 21 years ago, was largely stymied in its objectives because it was, and remained, a blueprint. It did not become part of a strategic plan to develop mental health services. There were no arrangements for financing, for bridging the old and the new, for creating the on-the-ground conditions for success. Another more recent example of the same failure of vision is to be found in the retrenchments surrounding the final enactment of the Disability Bill. ${ }^{8}$

It is against this background of concern and disillusionment that we come to examine some outstanding issues of immediate relevance to the implementation of this Act. How will adolescents fare under the new provision, now that the definition of childhood is extended to 18 years for the purposes of this Act? There is very little in the way of inpatient facilities for adolescents in this country. The same shortages of facilities apply to those with combined learning disabilities and psychiatric disorders. It appears as if the Act will be implemented in vacuo as it relates to these groups. The detention of those less than 18 years will require an application by the Health Service Executive (HSE) to the Courts. Has it been determined who within the HSE will make these applications, or what arrangements will be in place for out-of-hours cases?

The training programme developed by the MHC is only now being rolled out and still has quite some considerable way to go. An agreed administrative provision that would ensure full and prompt compliance with the act has not yet been determined. Of particular relevance to consultants is the failure to provide for the likely demands associated with operating the tribunal process. The argument that this should come within the scope of routine work is a reasonable one. However, difficulties are likely to occur.

Single-consultant sectors - single-person teams in many cases $^{9}$ - are the norm in this country, and hearings that coincide with outpatient clinics or other fixed clinical sessions might cause considerable disruption for patients. This potential difficulty will be amplified in those all-too-common situations where sector sizes are much larger than the recommended norms. 
Other matters also need addressing. Many, including the Irish Advocacy Network, would very sensibly, require second opinions to come from outside the service user's current service. How will the provision of these opinions be managed within the required time frame? Has any consideration been given to the geographical or logistical realities? What additional arrangements have been made for the short term when, in order to comply with the MHC's time frame of six months, all detained persons under the existing legislation will be reviewed? Has any progress been made yet on identifying who will act as the 'authorised officer' in the event of family unavailability or unwillingness to make an application for detention? We are all familiar with the inadequacy of the current legislation in this matter, where family members are put into sometimes irretrievably difficult situations. The delay in resolving this crucial matter is really unacceptable. If the authorised officers have finally been identified recently - have they received any training as yet? Or will we have to stumble on a resolution to this problem too on the day on which we are presented with the first real-life situation?

What about the fostering of collaboration between the Gardai (Irish Police Force) and the local health services so that we do not see a repetition of what I have observed: the inhumane business of a certified patient - who our society refers to as a person with an illness - being marched through the corridors of a hospital in handcuffs? Has the training begun for the Gardai yet? The provision of nursing escorts to ensure a humanitarian and caring rather than coercive approach to detention is an issue that has gone unresolved for over a decade now. On all of these issues we await clarification or practical proposals to offset the identified problems.

To return to the larger theme of this article, it is to be hoped that the concerns of the Act with issues of detention will lead to the identification of other less restrictive alternatives. If the Act is to be successful in terms of true freedom, of greater choice for patients, it needs to be recognised that there will be a large scale agenda for change that needs to be strategically planned and resourced. The experience of mental health legislation development elsewhere has been that such legislation has done little to improve access to and standards of treatment, to improve resources or to decrease social stigma and discrimination. ${ }^{10}$

This Act could underpin an aspiration to make the advance in civil liberties for our most vulnerable citizens a real, meaningful one. The UN Principles for the Protection of Persons with Mental IIIness has focused primarily on patients' rights, but also sets down resource standards, including the "provision of the same level of resources as any other health establishment whether in hospital or the community", and in particular that there should be "qualified medical and other professional staff in sufficient numbers and with adequate space to provide each patient with privacy and a programme of appropriate and active therapy".5

We all have ethical, legal and citizenry responsibilities to implement the Act as speedily and as fully as possible. To that end, the Irish Psychiatric Association asks that the parties involved in negotiations demonstrate flexibility and press for early implementation in recognition of the fundamental human right currently being denied to detained persons. It is our hope therefore that any differing perspectives on this matter yield to an approach that combines the imperatives of rights and care. As psychiatrists we must take our share of blame for having allowed a situation to persist such that we in Ireland now need to scramble to keep up with European Human Rights legislation. Let us not compound this error by now settling for a minimal response.

We should aim for a goal where, to quote again from the first of the UN Principles "all persons have the right to the best available healthcare". ${ }^{5}$ In pressing for the early implementation of this act, we need to redouble our efforts in advocating for quality services that will reflect the true spirit of the legislation.

\section{Dr lan Daly \\ On behalf of the Irish Psychiatric Association}

\section{References}

1.Department of Health and Children. The Mental Health Act 2001. The Stationery Office, Dublin, 2001.

2.Applebaum P. Almost a Revolution: Mental Health Law and the Limits of Change. Oxford University Press, New York, 1994. pp. 219.

3.Eastman N, Peay J. Law without enforcement. Theory and Practice, In: Law Without Enforcement; Integrating Mental Health and Justice (Eastman N, Peay J, eds). Hart Publishing, Oxford, 1998

4.Rose N. Psychiatry as a Political Science: Advanced Liberalism and the administration of Risk. History of the Human Sciences 1996; 9: 1-23

5.United Nations. Principles for the Protection of Persons with Mental lilness and for the Improvement of Mental Health Care. United Nations General Assembly 1991; 46th Session, Item No. 98(b)

6.O'Keane V, Walsh D, Barry S. The Black Hole. Irish Psychiatric Association, Dublin, 2005.

7. Department of Health. Planning for the Future, "Report of a Study Group on the Development of the Psychiatric Service", Stationery Office, Dublin, 1984.

8.Department of Justice, Equality and Law Reform. The Disability Bill. The Stationery Office, Dublin, 2001.

9.Denihan A, Consultants experiences during their first year in post. Irish Journal of Psychological Medicine 2005; 22: 3-4.

10. Human Rights and Equal Opportunity Commission. Human Rights and Mental Illness: Report of the National Enquiry into the Human Rights of People with Mental Illness (the Burdekin Report). Human Rights and Equal Opportunity Commission, AGPS, Canberra, 1993.

\section{Mental Health Commission}

Irish mental health legislation is grossly out of date, being based on the 1945 Mental Treatment Act. This Act belongs to a different era and no longer provides the basic rights and protections which must be available to people when they need to be compulsorily detained in a mental hospital. Shamefully, Ireland is in breach of international rights obligations enshrined in the European Convention of Human Rights and the United Nation Principles for the protection of the rights of those with mental illness. The medical profession has a key role in operating mental health legislation and psychiatrists have long been unhappy at being obliged to implement legislation that infringes the rights and dignity of their patients. It must, therefore, be a matter for considerable concern that the Mental Health Act 2001, so long awaited, has still not been fully commenced.

The Mental Health Act 2001, amongst other things, provides for an automatic independent right for a review of a decision to detain a patient. It also ensures the implementation of appropriate safeguards in relation to particular treatments and procedures. The Act has been criticised in not specifying rights to minimum standards of treatment. This of course, would be very difficult to provide for in legislation and the Act, for this reason, has established the Mental Health Commission with the dual responsibility of protecting the rights of those compulsorily detained and promoting and fostering high quality in the delivery of mental health services.

The rights and entitlements of those using the mental 
health services are of paramount importance to the Commission.

The Mental Health Commission sees itself as guardian of the Act and anticipates working very closely with all providers and users of mental health services in the radical reforms that are clearly required to modernise those services. A dynamic for change now exists with the Mental Health Act 2001, the establishment of the Mental Health Commission and, more recently, the setting up of an expert group to devise a new national mental health strategy and policy. Major developments can be anticipated in the mental health services and, in the context of these developments, there will be a clear need for extra resources.

The recent annual report of the Mental Health Commission, containing the report of the Inspector of Mental Health Services, describes very well the current deficiencies within the mental health services and the radical reforms required to address these deficiencies. It is evident from this report that the Mental Health Commission is fully aware of the resourcing problems within the mental health services and is committed to having these addressed.

There are remarkable variations in certification rates within Ireland, with a fourfold variation between catchments. There is no clear relationship between rates of certification and resource availability, with some of the highest certifying catchments having some of the highest levels of resource. This suggests that service organisation and clinical practice influence certification rates and the provision of extra resources alone will not lead to lower rates. What will affect certification rates is the development of more advanced community care models of service provision and the limitations to certification contained in the Mental Health Act 2001.

Should the Mental Health Act 2001 be implemented? Of course it should. It is understandable that consultant psychiatrists, who play a central role in the admission and review procedures, should be concerned about the effects the new Act will have on current practice and the use of their clinical time. What must be recognised, however, is that the protection of fundamental human rights and dignity must always be given priority in the provision of mental health services. This is evident in the WHO guiding principles for the organisation of mental health services: protection of human rights; accessibility; comprehensiveness; co-ordination and continuity of care; effectiveness; equity and efficiency (adapted from WHO, 2003').

In any quality mental health service priority must be given to the protection of human rights and this must be the priority in any discussion of resource allocation. There is certainly a need for substantial investment in mental health services but current deficiencies should not be allowed to delay the implementation of legislation which gives essential protection to human rights and freedoms. The recommendations for service development have been described in the recent report of the Mental Health Commission and the extra resource becoming available in the context of the now accepted need for radical reform of the mental health services will be influenced by these recommendations.

In the last year in particular, the Mental Health Commission has undertaken a vast amount of work in preparation for the commencement of Part 2 of the Mental Health Act 2001. The co-operation of consultant psychiatrists in taking up appointments to mental health tribunals and as second examining consultants is now required to prevent delay in its commencement.

The current situation where the commencement of Part 2 of the Act is not being supported by some consultant psychiatrists is most unfortunate. While the concern of psychiatrists may be understandable, psychiatrists are now unfortunately in a position where they are perceived by an increasingly cynical media and uncomprehending public as holding-up the implementation of legislation that protects the fundamental rights of their patients. Professional bodies representing psychiatrists need to provide guidance and leadership at this crucial time.

\section{Dr John Owens \\ Chairman \\ Mental Health Commission}

Reference

1. World Health Organisation Regional Office for Europe's Health Evidence

Network. What are the arguments for community-based mental healthcare? Copenhagen: World Health Organisation, 2003. (available at: www.euro.who.int/ document/E82976.pdf).

\section{Cover Image: 'Truth Hole 2005'}

Anthony Kelly's work endeavours to document aspects of the human condition through the use of human generic forms and shapes; zooming in, slowing down, freezing, suspending, observing repetition, noting minor change. Part of the structure comes from margins of pages of second or third generation photocopies which have been discarded. These marks are enlarged again on a photocopier, scanned and collaged using digital software. The images form as these shapes cross fade - sometimes imagined - in and out of each other. They build themselves on precise or random markings and layers of bold colours. There is an edition of seventy of each print. Truth Hole is one of the works hanging in St. James's Hospital through the Artist's Loan Scheme 


\section{Ebixa ${ }^{\curvearrowleft}$ - works like no other treatment}

\section{Ebixa is the first and only product in a new class of drugs for Alzheimer's Disease}
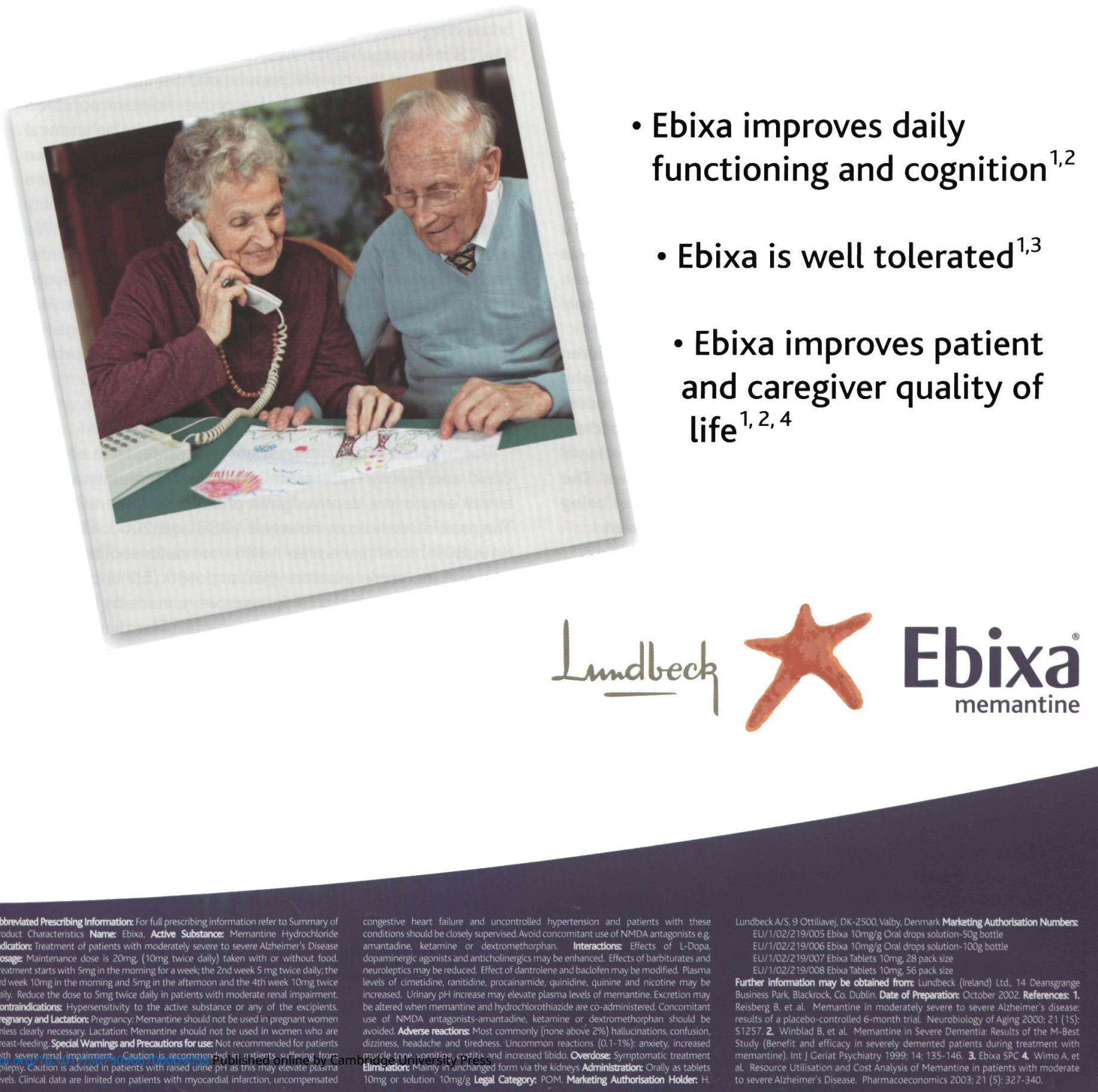